\title{
Changing the Growth Behavior of a NiSn-Solder Using Gold
}

\author{
Mathias Wendt'1,2, Andreas Weimar'2, Marcus Zenger², Klaus Dilger'1 \\ ${ }^{1}$ Institut für Füge-und Schweißtechnik, Technische Universität Braunschweig, Braunschweig, Germany \\ ${ }^{2}$ Osram Opto Semiconductors GmbH, Regensburg, Germany \\ Email: mathias.wendt@osrsam-os.com
}

Received 31 March 2016; accepted 25 April 2016; published 28 April 2016

Copyright () 2016 by authors and Scientific Research Publishing Inc.

This work is licensed under the Creative Commons Attribution International License (CC BY).

http://creativecommons.org/licenses/by/4.0/

\section{(c) (7) Open Access}

\begin{abstract}
In this investigation, the influence of a thin gold ( $\mathrm{Au}$ ) layer on the growth behavior of the intermetallic compound (IMC) in a Nickel-Tin-Solder (NiSn-Solder) was studied. The reaction kinetics was studied in the temperature range of $232^{\circ} \mathrm{C}$ to $330^{\circ} \mathrm{C}$ using cross-sectional scanning electron microscope (SEM) images. The kinetics of the reaction was determined using the empirical power law and the research showed that the introduction of an Au layer changes the reaction kinetics of the solder significantly. Furthermore, the change in reaction kinetics was accompanied by a change in morphology of the developing grains. The grain morphology of the IMC was studied for samples annealed at $290^{\circ} \mathrm{C}$ using cross-sectional and top-view samples and compared to Au free NiSnSolder.
\end{abstract}

\section{Keywords}

Lead-Free Solder, Intermetallic Compound Formation, Grain Growth

\section{Introduction}

The study presented previously focused on the influence of temperature on the morphology and growth kinetic of $\mathrm{Ni}_{3} \mathrm{Sn}_{4}$ in a NiSn-Solder system [1]. The study showed that at temperatures above $290^{\circ} \mathrm{C} \mathrm{Ni}_{3} \mathrm{Sn}_{4}$ grew in a needle like morphology. Since the needle-like growth could cause issues when using the solder as an interconnection, the influence of additional metal layers on the growth behavior of the solder were studied. In this investigation, the change in reaction kinetics and growth behavior of the IMC in a NiSn-Solder due to a thin Au-layer was studied in the temperature range of $232^{\circ} \mathrm{C}$ to $330^{\circ} \mathrm{C}$ using cross-sectional and top-view SEM images. The focus of this research was based on the influence of the added $\mathrm{Au}$ on the IMC formation, its growth kinetics and the morphology of the developing grains. The difference between a NiSn-Solder and an AuNiSn-Solder would be discussed in detail. 


\section{Materials and Methods}

The metal stack used in this investigation was deposited onto a $150 \mathrm{~mm}$, p-doped (boron), single flat silicon wafer with a (100) surface normal, and an initial thickness of $625 \mu \mathrm{m}$, using sputtering in high vacuum. All materials used for the investigation are grade 5N (99.999\% pure) materials. The deposition was done using a commercially available cluster tool for the physical vapor deposition of thin films. The material stack consists of a Titanium (Ti) adhesion layer, deposited on the native oxide of the silicon wafer. After the Ti adhesion layer a nickel layer, with a thickness of $500 \mathrm{~nm}$, was deposited followed by a $120 \mathrm{~nm}$ layer of Au, and a $1000 \mathrm{~nm}$ thick layer of Tin (Sn) which was covered with $100 \mathrm{~nm}$ Ti to prevent the oxidation of the Sn. The process gas used during the sputtering processes was Argon. During deposition the wafers remained in a high vacuum, ensuring that the materials remain oxygen and contaminant free. After the deposition of the material stack, the wafer was thinned to a thickness of $150 \mu \mathrm{m}$ using a standard wafer thinning process. The samples used to determine the growth kinetic of the IMC are square pieces with a side length of $1.4 \mathrm{~mm}$, the samples used to determine the morphology of the grains at $290^{\circ} \mathrm{C}$ and $10 \mathrm{~s}$ of annealing are square pieces with a side length of approximately 1 $\mathrm{cm}$, the preparation procedures for the samples will be explained in the respective sections.

\subsection{Determining IMC Growth Kinetics}

In order to generate samples for the determination of the growth kinetics of the IMC, the $150 \mu \mathrm{m}$ thick wafer is separated into square pieces with a side length of $1.4 \mathrm{~mm}$ using a low power, nano-second, laser dicing process. During the processing of the wafer great care was taken not to expose it to temperatures above room temperature, in order to eliminate the possibility of the materials reacting before the experiments. Additionally, during the SEM investigation, only regions outside of the heat effected zone of the laser dicing process were used for analysis, in order not to alter the results of the annealing experiments. The samples were annealed at the temperatures $232^{\circ} \mathrm{C}, 260^{\circ} \mathrm{C}, 290^{\circ} \mathrm{C}, 310^{\circ} \mathrm{C}$, and $330^{\circ} \mathrm{C}$ for various annealing durations $(1 \mathrm{~s}, 3 \mathrm{~s}, 5 \mathrm{~s}, 10 \mathrm{~s}, 30 \mathrm{~s}, 60 \mathrm{~s})$ using a heated bond head tool. The process used for annealing is described in detail by Wendt et al. [1].

To determine the growth of the IMC during annealing the cross-section of the samples was investigated using scanning electron microscope (SEM) images. In order to generate a clear SEM image of the cross-section, the samples were embedded into an epoxy resin, ground, polished, ion milled, and a thin Gold-Palladium film was deposited on the surface of the sample to ensure conductivity and avoid charging of the sample during SEM analysis. The cross-section of an as-deposited sample embedded into an epoxy resin is displayed in Figure 1.

\subsection{Determining IMC Morphology}

The samples used for determining the morphology of the IMC are square pieces with a side length of approximately $1 \mathrm{~cm}$. They were generated by initiating cracks with a diamond tipped stylus on the surface of the 150 $\mu \mathrm{m}$ thick wafer in the desired grid and then separating the wafer into pieces. The pieces were annealed using a hot plate (Präzitherm, PZ 28-2T) at a temperature of $290^{\circ} \mathrm{C}$ for $10 \mathrm{~s}$. After annealing the remaining elementary

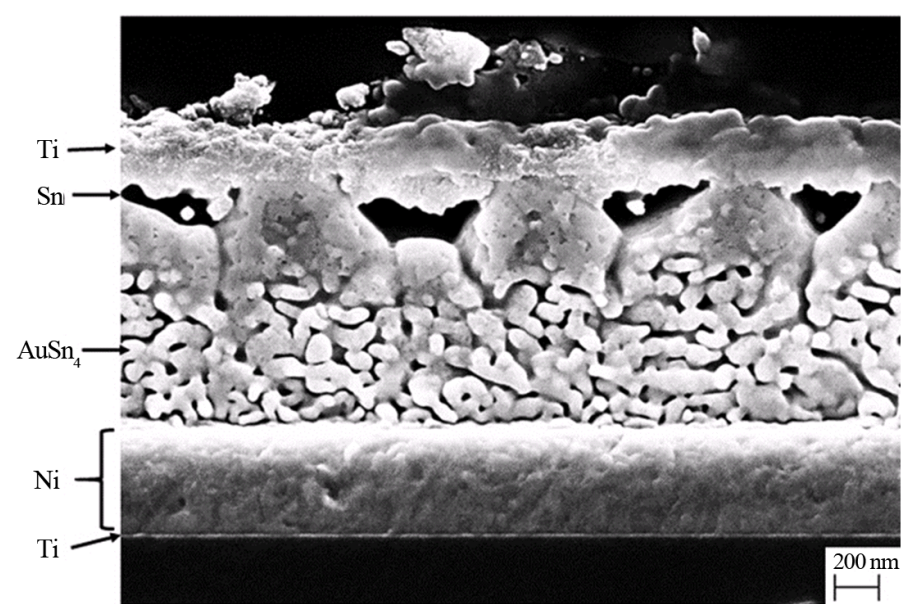

Figure 1. Cross-sectional SEM image of the as-deposited sample. 
Sn and parts of the $\mathrm{AuSn}_{4}$ were selectively etched away using an aqueous solution of $\mathrm{HCl}$ (38\%) and $\mathrm{H}_{3} \mathrm{PO}_{4}$ (85\%), an etch duration of $60 \mathrm{~s}$ was selected in order not to over etch the samples, the solution was kept at room temperature during etching.

\subsection{Analytical Methods}

The morphology, and chemical composition of the IMC formed during heat treatment was investigated using a Zeiss Leo Gemini 1530 SEM, and an AMETEK EDAX APOLLO X silicon drift detector.

\section{Results and Discussion}

The growth kinetic of the IMC was studied using cross-sectional samples. Investigating samples after deposition showed that the Au and the Sn layer already reacted to form a mixture of $\mathrm{AuSn}_{4}$ and $\mathrm{Sn}$, as seen in Figure 1. The solid state diffusion in the Au/Sn system and the reaction of $\mathrm{Au}$ and $\mathrm{Sn}$ in the solid state has been studied extensively in the literature which concluded that the Au diffuses into Sn via bulk diffusion and Sn diffuses into $\mathrm{Au}$ via grain-boundary diffusion. If this occurs in an environment with excess of $\mathrm{Sn}, \mathrm{AuSn}_{4}$ can form [2] [3]. The results of the references were also in accordance with the EDX analysis of the $\mathrm{AuSn}_{4}$ grains in the as deposited samples, one of which is displayed in Figure 2(a). When annealing the samples at temperatures above the melting point of $\mathrm{Sn}$, the formation of an IMC containing $\mathrm{Ni}, \mathrm{Au}$, and $\mathrm{Sn}$ can be observed. At this state, the liquid component of the solder is a mixture of Au and Sn with, depending on the temperature of the solution, some remaining $\mathrm{AuSn}_{4}$ in the solid state [4]. When cooling the samples back to room temperature the liquid component of the solder solidifies and segregates into $\mathrm{AuSn}_{4}$ grains in a Sn matrix. Since SEM images are recorded of the material stack in this configuration, the component of the solder which is in the liquid state during the annealing will be attributed to as $\mathrm{AuSn}_{4}$ in a Sn matrix in the SEM images when in fact the liquid component is simply a mixture of Au and Sn during the reaction. EDX analysis was used to determine the composition of the IMC and the results showed that a compound with a composition of approximately $15 \mathrm{at} \% \mathrm{Au}, 30 \mathrm{at} \% \mathrm{Ni}$ and $55 \mathrm{at} \% \mathrm{Sn}$ had formed, at all annealing temperatures. One of the EDX measurements used to determine the composition is shown in Figure 2(b).

The IMC composition is closest to the compound $\mathrm{AuNi}_{2} \mathrm{Sn}_{4}$ which was first reported by Neumann et al. [5]. For all further analysis we will assume that the phase formed is in fact $\mathrm{AuNi}_{2} \mathrm{Sn}_{4}$. At low annealing temperatures $\left(232^{\circ} \mathrm{C}\right.$ and $260^{\circ} \mathrm{C}$ ) the growth occurs in a layer type morphology, at a temperature of $290^{\circ} \mathrm{C}$ the IMC grows rougher and the spalling of individual grains into the solder can be observed. Figure 3 displays samples annealed at $232^{\circ} \mathrm{C} \mathrm{a}$ ), $290^{\circ} \mathrm{C} \mathrm{b}$ ) and $330^{\circ} \mathrm{C} \mathrm{c}$ ) for $10 \mathrm{~s}$, the IMC changes from a layer type morphology, seen in Figure 3(a), to an increasingly rough morphology Figure 3(b) and Figure 3(c).

The cross-section images of samples annealed at $290^{\circ} \mathrm{C}$ and above show that the $\mathrm{AuNi}_{2} \mathrm{Sn}_{4}$ grows in large rounded grains. In the NiSn-Solder system a needle-like growth of $\mathrm{Ni}_{3} \mathrm{Sn}_{4}$ is observed at these particular temperatures, which is discussed by Wendt et al. [1]. The change in the IMC morphology is attributed to the Au added to the solder system. The cross-sectional samples annealed at $310^{\circ} \mathrm{C}$ are displayed in Figure 4 .

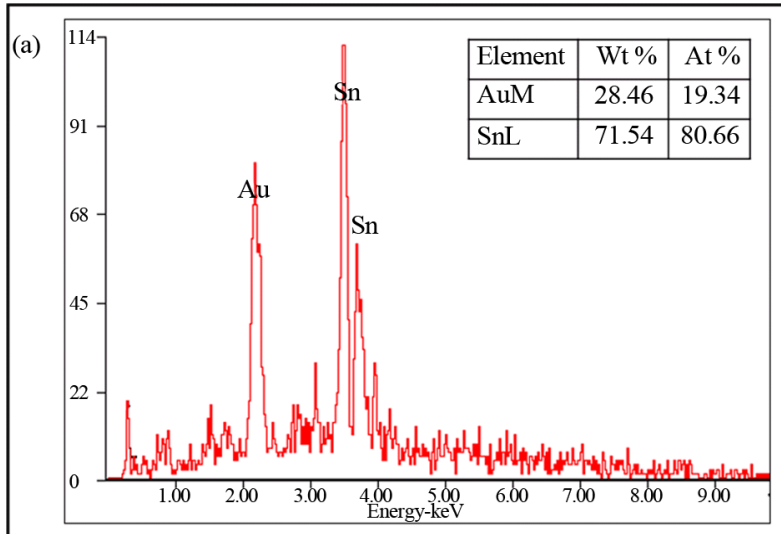

(b)

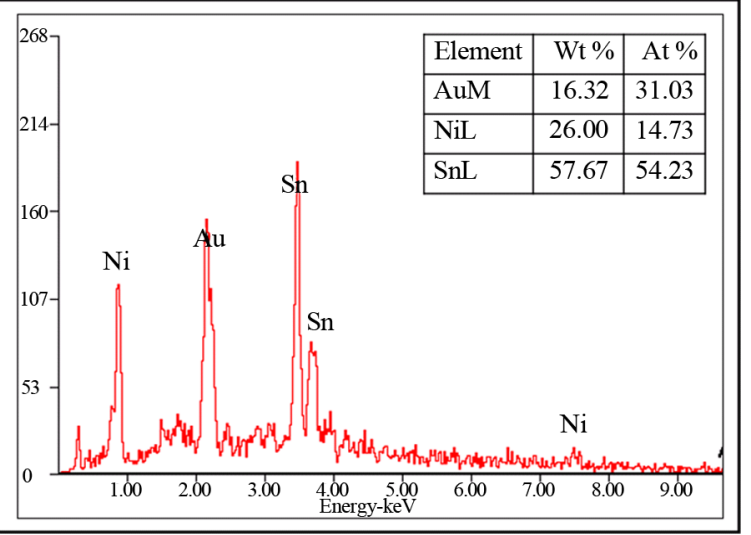

Figure 2. EDX measurements of $\mathrm{AuSn}_{4}$ grains in $\mathrm{Sn}$ matrix (a) and of the $\mathrm{AuNi}_{2} \mathrm{Sn}_{4}$ IMC formed during the intermetallic reaction (b). 

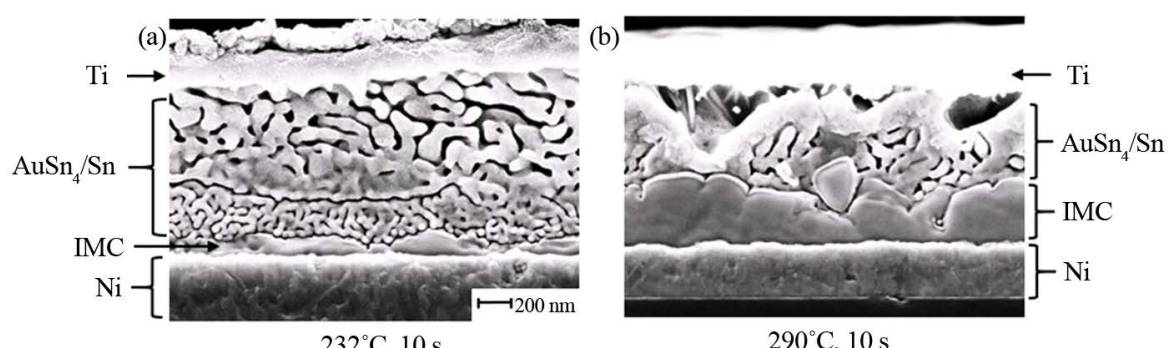

$232^{\circ} \mathrm{C}, 10 \mathrm{~s}$

$290^{\circ} \mathrm{C}, 10 \mathrm{~s}$

(c)

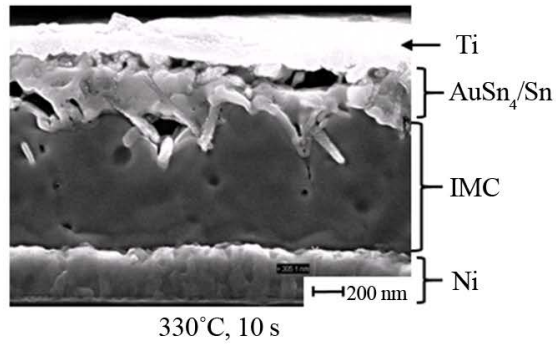

Figure 3. Cross-sectional SEM images of samples annealed at $232^{\circ} \mathrm{C} \mathrm{(a),} 290^{\circ} \mathrm{C}$ (b) and $330^{\circ} \mathrm{C}(\mathrm{c})$ for $10 \mathrm{~s}$ and embedded into an epoxy resin.
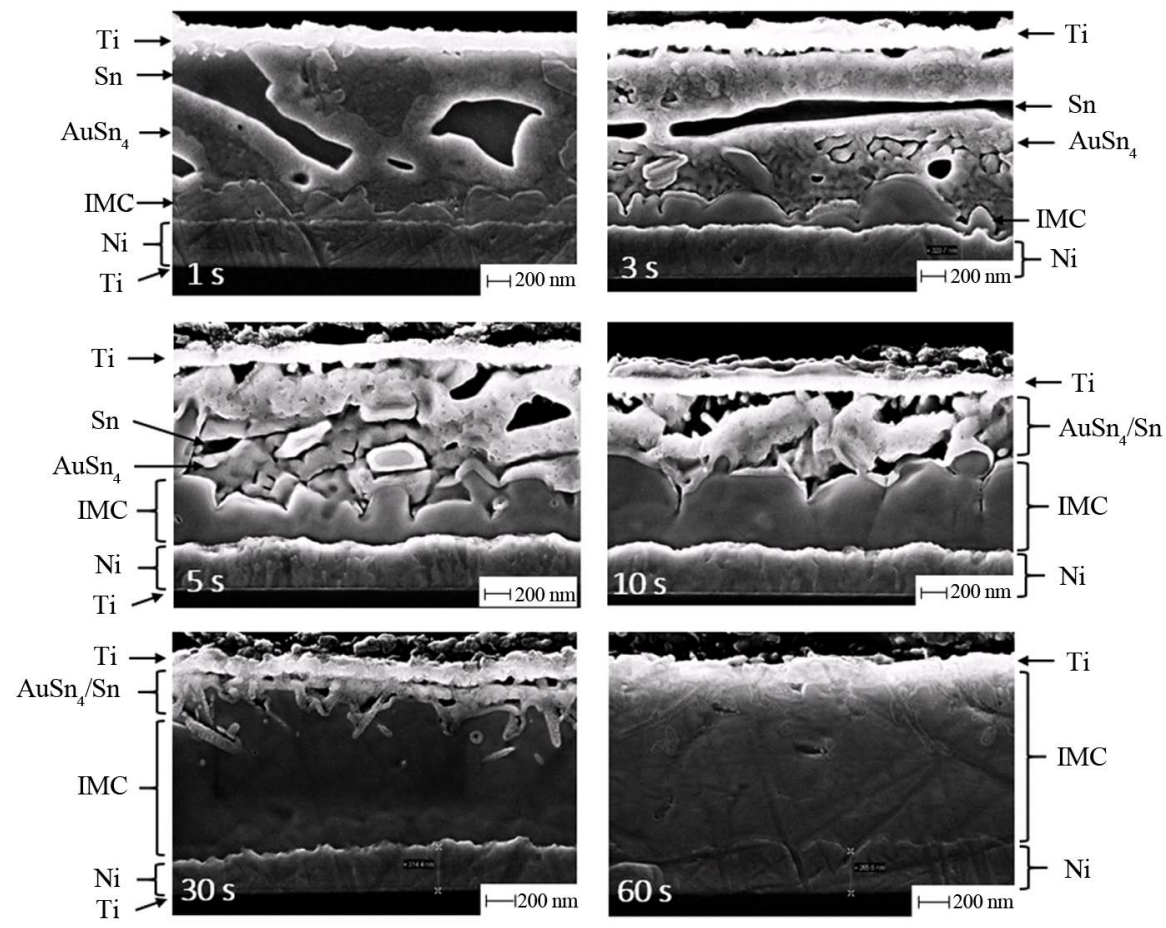

Figure 4. Cross-sectional SEM images of samples annealed at $310^{\circ} \mathrm{C}$ for $1 \mathrm{~s}, 3 \mathrm{~s}, 5 \mathrm{~s}, 10 \mathrm{~s}$, $30 \mathrm{~s}, 60 \mathrm{~s}$ and embedded into an epoxy resin.

As seen in Figure 4, the growth of the IMC occurs at the interface between the Ni and the liquid component of the solder, $\mathrm{AuSn}_{4} / \mathrm{Sn}$. The growing IMC appears as a continuous layer with an irregular interface towards the $\mathrm{AuSn}_{4} / \mathrm{Sn}$. The growth kinetic of the IMC was determined using the cross-sectional SEM images of the embedded samples and the empirical power law in the following form:

$$
X=X_{0}+k t^{n} .
$$

where $X$ represents the thickness of the IMC at time $t, X_{0}$ represents the thickness at $t=0, k$ is the rate constant 
of the reaction, and $n$ is the time exponent. The empirical power law is frequently used to describe the growth of intermetallic compounds and the value of $n$ gives important insight into the growth rate controlling steps in the reaction. Solid state diffusion controlled reactions exhibit a parabolic dependence of IMC layer thickness on time, while grain-boundary diffusion controlled reactions often show a $t^{1 / 3}$ dependence [6]. The irregular interface between the Ni and the IMC as well as the IMC and the liquid component of the solder makes it difficult to measure the thickness of the IMC, therefore the decrease of the Ni thickness as a function of time was used to determine the growth rate of the IMC. In order to analyze the growth behavior following assumptions are made:

1) The decrease in Ni thickness is directly proportional to the increase in IMC thickness

2) The solubility of $\mathrm{Ni}$ in the liquid $\mathrm{AuSn}_{4} / \mathrm{Sn}$ is negligible

3) The growth of the IMC during heating and cooling is negligible

Assumption 1 is valid if the IMC in question is constituted of only one phase, $\mathrm{AuNi}_{2} \mathrm{Sn}_{4}$, with a constant $\mathrm{Ni}$ concentration, which is in accordance with our EDX results, and if assumption 2 is valid. Since the amount of Ni detected using EDX analysis in the $\mathrm{AuSn}_{4} / \mathrm{Sn}$ section of the cross-sectional samples is 2 at\% and lower, and since the solubility of $\mathrm{Ni}$ in liquid $\mathrm{Sn}$ is less than 1 at\%, assumption 2 is considered to be valid [7]. Furthermore, due to the low thermal mass of the chips and good heat transfer from the HBH to the chip, short heating and cooling periods can be realized with the annealing method used, therefore assumption 3 is valid.

The amount of Ni consumed was plotted versus annealing time in a logarithmic plot to determine the time exponent $n$, as seen in Figure 5.

The time exponent $\mathrm{n}$ was determined for all annealing temperatures, the results are displayed in Table 1.

The resulting value of $n$ was expected to be similar to the result of $\mathrm{Ni}_{3} \mathrm{Sn}_{4}$, which was determined to be in the range of 0.26 to 0.33 by Wendt et al. but the current results show that it is significantly lower, which could not be matched to a currently known growth model [1] [6]. These results show that the addition of Au to the solder does not only change the morphology of the growing grains but also the growth rate controlling mechanism.

\subsection{Difference in Morphology of $\mathrm{Ni}_{3} \mathrm{Sn}_{4}$ and $\mathrm{AuNi}_{2} \mathrm{Sn}_{4}$}

The IMC morphology of the growing $\mathrm{AuNi}_{2} \mathrm{Sn}_{4}$ was investigated using etched samples and compared the results presented in [1]. The samples were annealed for short periods of time and the remaining $\mathrm{Sn}$ and parts of the $\mathrm{AuSn}_{4}$ layer of the solder were removed. Images of the exposed IMC were recorded using the SEM. The images of the top-view and cross-sectional view of these samples enable the observer to get an almost 3-dimensional view and therefore good understanding of the IMC morphology. Figure 6 displays a direct comparison between a NiSn-Solder and an AuNiSn-Solder sample, both annealed at $290^{\circ} \mathrm{C}$ for $10 \mathrm{~s}$.

The top-view and cross-section SEM images of the NiSn-Solder sample displayed in Figure 6(a) show the needle-like growth of $\mathrm{Ni}_{3} \mathrm{Sn}_{4}$ previously presented by Wendt et al. [1]. The top view of the AuNiSn-Solder sample, displayed in Figure 6(b), shows a direct view onto the $\mathrm{AuNi}_{2} \mathrm{Sn}_{4}$ grains, while the cross-sectional view

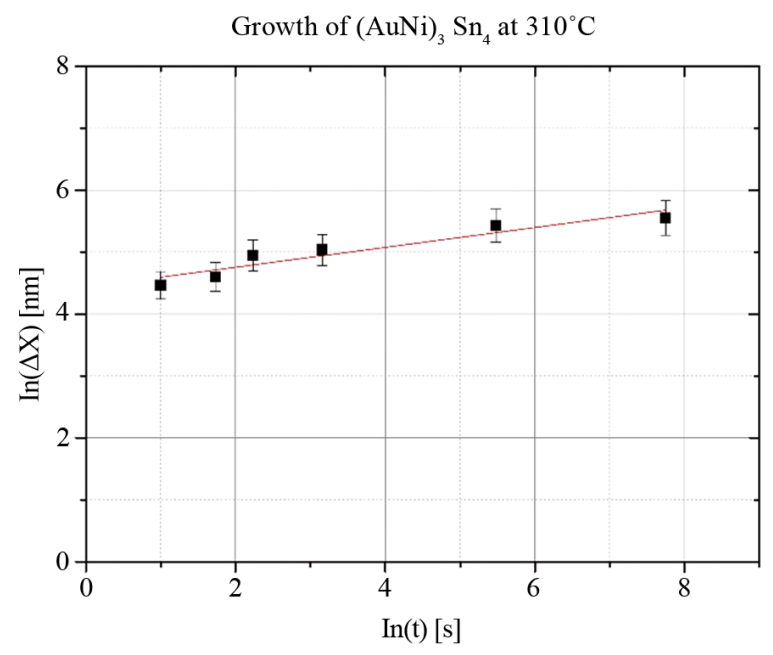

Figure 5. Logarithmic plot of the change in Ni thickness versus time for the annealing temperature $310^{\circ} \mathrm{C}$, used to determine the time exponent $n$. 
Table 1. Results of time exponent $n$.

\begin{tabular}{cc}
\hline $\mathrm{T}\left[{ }^{\circ} \mathrm{C}\right]$ & $n$ \\
$232^{\circ} \mathrm{C}$ & 0.12 \\
$260^{\circ} \mathrm{C}$ & 0.13 \\
$290^{\circ} \mathrm{C}$ & 0.18 \\
$310^{\circ} \mathrm{C}$ & 0.16 \\
$330^{\circ} \mathrm{C}$ & 0.12 \\
\hline
\end{tabular}
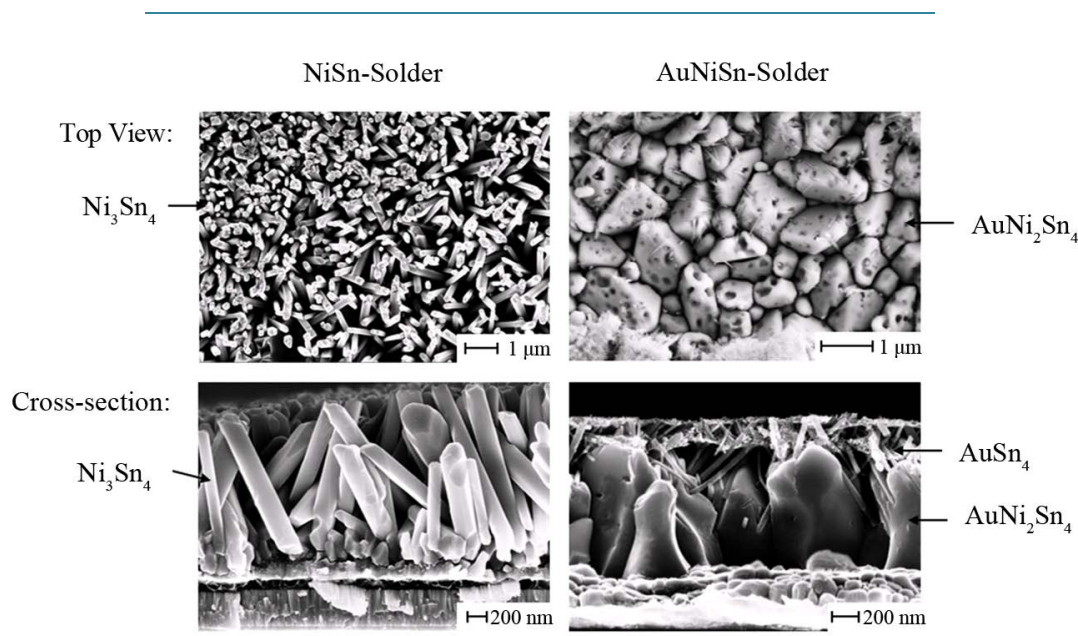

(a)

(b)

Figure 6. Top-view and cross-sectional SEM images of etched samples annealed at $290^{\circ} \mathrm{C}$ for $10 \mathrm{~s}$, (a) NiSn-Solder and (b) AuNiSn-Solder.

displays the $\mathrm{AuNi}_{2} \mathrm{Sn}_{4}$ grains with some remaining $\mathrm{AuSn}_{4}$ on top. The $\mathrm{AuSn}_{4}$ grains also display a needle-like morphology which is attributed to the solidification morphology of the compound when cooled from temperatures above the melting point of the solder. This effect has been previously observed and is reported in the literature [8] [9]. The main difference in the solder layer between the two samples is an additional $120 \mathrm{~nm}$ thick layer of Au between the Ni and the Sn in the AuNiSn-Solder samples. It is clearly visible in the images that the Au layer has a pronounced effect on the morphology of the IMC. While the IMC in the NiSn-Solder samples grows in a needle-like shape at $290^{\circ} \mathrm{C}$, the IMC in the AuNiSn-Solder sample grows in large-rounded grains.

\subsection{The Growth Mechanism and the Spalling of Grains in AuNiSn-Solder}

Since the time exponent $n$ differed significantly form the results expected, the investigation focused to find the reason responsible for the deviation from the expected results. A close look at the interface between the IMC and the liquid component of the solder as well as the solid component of the solder can give insight into the mechanism controlling the IMC growth. When investigating the cross-sectional SEM images of the embedded samples, individual $\mathrm{AuNi}_{2} \mathrm{Sn}_{4}$ grains were observed spalling from the IMC layer. Figure 7 displays an embedded sample with spalling grains in the $\mathrm{AuSn}_{4} / \mathrm{Sn}$.

The spalling of grains is often attributed to the crumbling mechanism, proposed by Görlich et al. [10]. They claim that, in the case of NiSn-Solder, the separation of individual grains from the IMC interface is caused by smaller grains growing at the interface between the IMC and the Ni which push the grains above into the liquid component of the solder. The growth of the smaller grains occurs at the intersection of grain-boundaries and the $\mathrm{Ni}$ layer. The growth of these $\mathrm{Ni}_{3} \mathrm{Sn}_{4}$ grains is driven by the diffusion of the liquid component of the solder along grain-boundaries of the IMC towards the $\mathrm{Ni}$, which was also confirmed by Wendt et al. [1]. When investigating the grain-boundaries of the $\mathrm{AuNi}_{2} \mathrm{Sn}_{4}$ small grains can be found at the intersection of grain-boundaries with the Ni layer. Therefore we conclude that the spalling of $\mathrm{AuNi}_{2} \mathrm{Sn}_{4}$ grains into the solder is driven by the crumbling mechanism proposed by Görlich et al. Furthermore we conclude that the liquid component of the 


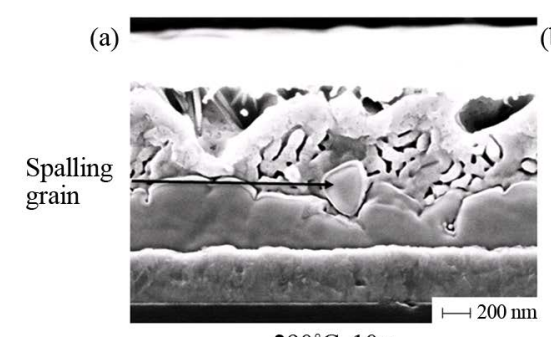

$290^{\circ} \mathrm{C}, 10 \mathrm{~s}$

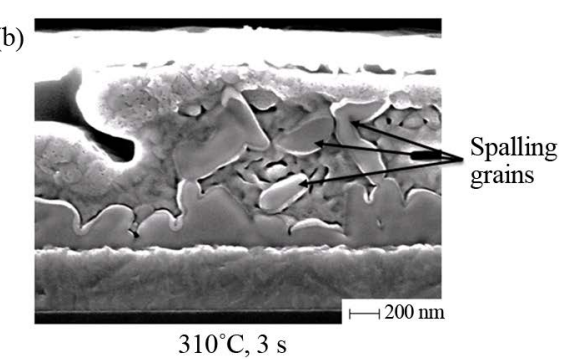

$310^{\circ} \mathrm{C}, 3 \mathrm{~s}$

Figure 7. Cross-sectional SEM images of samples annealed at (a) $290^{\circ} \mathrm{C}, 10 \mathrm{~s}$ and (b) $310^{\circ} \mathrm{C}, 3 \mathrm{~s}$ with $\mathrm{AuNi}_{2} \mathrm{Sn}_{4}$ grains spalling into the $\mathrm{AuSn}_{4} / \mathrm{Sn}$.

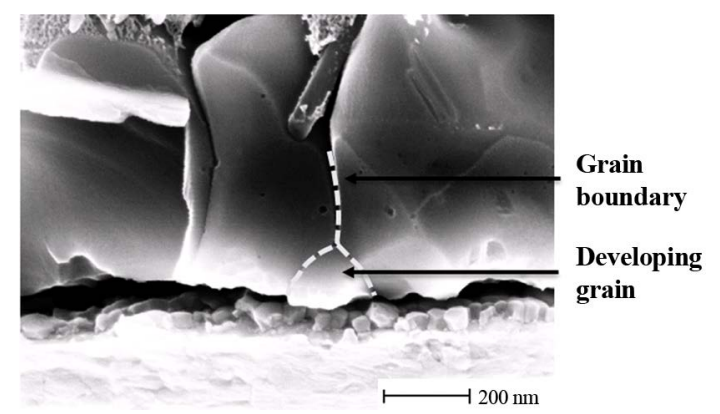

Figure 8. Cross-sectional SEM image of an etched sample, the sample was annealed at $290^{\circ} \mathrm{C}$ for $10 \mathrm{~s}$.

solder moves along grain-boundaries towards the Ni during the growth of the IMC. Figure 8 is a cross-sectional image of an etched sample displaying the grain-boundary between two $\mathrm{AuNi}_{2} \mathrm{Sn}_{4}$ grains, highlighted in the image using a dashed line, and a developing grain at the intersection between the grain-boundary and the Ni layer. In view of these results and the value of $n$ determined, we conclude that the transport of the liquid component of the solder occurs along the grain-boundaries but the transport seems not to be the rate controlling step of the reaction during the IMC growth, as is usually the case for IMC growth. The rate controlling step of the reaction remains unknown and further studies of the system are required to determine the cause for the low values of the time exponent $n$.

\section{Conclusion}

The reaction of an AuNiSn-Solder was studied in the temperature range of $232^{\circ} \mathrm{C}$ to $330^{\circ} \mathrm{C}$. The growth kinetic was analyzed using the empirical power law and the time exponent $n$ was determined to be between 0.12 and 0.18. Additionally, the morphology of the grains was studied using cross-sectional and top-view SEM images of etched samples and a comparison between a NiSn-Solder and the AuNiSn-Solder was made. It became clear that the Au layer had a pronounced effect on the time exponent $n$ of the IMC growth as well as on the morphology of the developing grains. The crumbling of IMC grains into the solder was observed and could be linked to the crumbling mechanism proposed by Görlich et al. Additionally, the cross-sectional SEM images showed that the grain-boundaries seemed the be a preferred transport path of the liquid component of the solder towards the $\mathrm{Ni}$ interface, causing new grains to develop at the intersections between the grain-boundaries and the Ni layer.

\section{References}

[1] Wendt, M., Plößl, A., Weimar, A., Zenger, M. and Dilger, K. (2016) Investigation of the Influence of Annealing Temperature on the Morphology and Growth Kinetic of $\mathrm{Ni}_{3} \mathrm{Sn}_{4}$ in the Ni-Sn-Solder System. Journal of Materials Science and Chemical Engineering, 4, 116-130. http://dx.doi.org/10.4236/msce.2016.42013

[2] Nakahara, S. and McCoy, R. (1980) Kirkendall Void Formation in Thin-Film Diffusion Couples. Applied Physics Letters, 37, 42-44. http://dx.doi.org/10.1063/1.91696

[3] Buene, L., Falkenberg-Arell, H., Gjønnes, J. and Taftø, J. (1980) A Study of Evaporated Gold-Tin Films Using Transmission Electron Microscopy: II. Thin Solid Films, 67, 95-102. http://dx.doi.org/10.1016/0040-6090(80)90292-8 
[4] Okamoto, H. and Massalski, T.B. (1984) The Au-Sn (Gold-Tin) System. Bulletin of Alloy Phase Diagrams, 5, 492. http://dx.doi.org/10.1007/BF02872904

[5] Neumann, A., Kjekshus, A., Romming, C. and Rost, E. (1995) The Crystal Structure of $\mathrm{AuNi}_{2} \mathrm{Sn}_{4}$. Journal of Solid State Chemistry, 119, 142-146. http://dx.doi.org/10.1016/0022-4596(95)80021-G

[6] Schaefer, M., Fourelle, R.A. and Liang, J. (1998) Theory of Intermetallic Phase Growth between Cu and Liquid Sn-Pb Solder Based on Grain Boundary Diffusion Control. Journal of Electronic Materials, 27, 1167-1176. http://dx.doi.org/10.1007/s11664-998-0066-7

[7] Liu, H.S., Wang, J. and Jin, Z.P. (2004) Thermodynamic Optimization of the Ni-Sn Binary System. Calphad, 28, 363370. http://dx.doi.org/10.1016/j.calphad.2004.12.002

[8] Minor, A.M. and Morris Jr., J.W. (2000) Growth of a Au-Ni-Sn Intermetallic Compound on the Solder-Substrate Interface after Aging. Metallurgical and Materials Transactions A, 31, 798-800. http://dx.doi.org/10.1007/s11661-000-0022-5

[9] Glazer, J., Kramer, P. and Morris Jr., J.W. (1991) Effect of Au on the Reliability of Fine Pitch Surface Mount Solder Joints. Proceedings of the Surface Mount International Conference, 1.2, 629-639.

[10] Görlich, J., Baither, D. and Schmitz, G. (2010) Reaction Kinetics of Ni/Sn Soldering Reaction. Acta Materialia, 58, 3187-3197. http://dx.doi.org/10.1016/j.actamat.2010.01.027 